\title{
Study on Thermosonication and Ultraviolet Radiation Processes as an Alternative to Blanching for Some Fruits and Vegetables
}

\author{
Elisabete M. C. Alexandre - Dora M. Santos-Pedro • \\ Teresa R. S. Brandão • Cristina L. M. Silva
}

\begin{abstract}
The impacts of ultraviolet-C radiation, blanching by heat, and combination of heat/ultrasounds (thermosonication) were studied for Listeria innocua (inoculated) in red bell peppers, total mesophiles in strawberries and total coliforms in watercress, in the temperature range $50-65{ }^{\circ} \mathrm{C}$. Quality attributes such as colour and firmness were studied for all products, and total anthocyanins content was additionally determined for strawberries. Results showed that ultraviolet$\mathrm{C}$ radiation was the least effective treatment in terms of microbial load reduction and was equivalent to a simple water washing. $\log$ reductions were $1.05 \pm 0.52$ for $L$. innocua, $0.53 \pm 0.25$ for total coliforms and $0.26 \pm 0.18$ for total mesophiles. This treatment had the lowest impact on the quality parameters analysed. Thermosonication treatment was similar to heat blanching for all microorganism/product tested, excepted for total coliforms in watercress at $65^{\circ} \mathrm{C}$, in which thermosonication had a higher effect $(p<0.05)$. Heat blanching at $65{ }^{\circ} \mathrm{C}$ allowed $7.43 \pm 0.12$ log-cycles reduction, while loads were diminished by $8.24 \pm 0.13$ log-cycles if thermosonication at the same temperature was applied. Thermosonication also allowed better quality retention, when compared to heat blanching at the same temperatures. The impact of thermosonication on microbial load reductions was statistically significant and thermosonicated samples retained quality attributes better than heat blanched ones at the same temperatures $(p<0.05)$. Hence, it can be concluded that thermosonication is a promising process and may be a favourable alternative to the conventional thermal treatments.
\end{abstract}

E. M. C. Alexandre • D. M. Santos-Pedro • T. R. S. Brandão •

C. L. M. Silva $(\bowtie)$

CBQF - Centro de Biotecnologia e Química Fina,

Escola Superior de Biotecnologia,

Universidade Católica Portuguesa,

Rua Dr. António Bernardino de Almeida,

4200-072 Porto, Portugal

e-mail: clsilva@esb.ucp.pt
Keywords Ultraviolet-C radiation - Thermosonication . Blanching · Microbial load reduction · Quality ·

Fruits and vegetables

\section{Introduction}

One of the most applied treatments to stabilize fruits and vegetables is blanching. The effect of heat on microorganisms and enzymes responsible for deteriorative reactions makes thermal processes confiding treatments. However, undesirable nutrient losses, and organoleptic and textural changes may occur due to the negative impact of heat on fruit and vegetable tissues (Mukherjee and Chattopadhyay 2007; Sotome et al. 2009; Cruz et al. 2009). From an industrial point of view, thermal processes are extremely energy consuming and have high environmental impacts. Therefore, there is a growing interest on the application of minimal process technologies for attaining less-perishable products, safe from a microbiological perspective, while retaining quality attributes close to the fresh characteristics (Ahvenainen 1996). Alternative nonthermal processes, or eventually their combinations with less severe heat treatments, are emergent challenges. The application of ultrasounds and ultraviolet (UV) irradiation are examples with potential applications in the food industry (Allende and Artés 2003a; Piyasena et al. 2003). Ultrasound is defined as sound waves with a frequency over $20 \mathrm{kHz}$, which is about the upper limit of human hearing. When applied to a product with sufficient intensity, it causes disruption of biological structures, resulting in cell death. Ultrasounds, when associated to heat (thermosonication) and pressure (manosonication), have been reported to inactivate microorganisms as well as heat resistant enzymes (Vercet et al. 1997; Knorr et al. 2004; Cruz et al. 2006). The conjoint application of thermal treatments with 
ultrasounds may enhance their effects, especially in terms of product safety (Mason et al. 1996; Char et al. 2010). Some authors refer a microbial reduction between 5 and 6 log-cycles for liquid foods treated with power ultrasounds combined with mild thermal treatments (Baumann et al. 2005; D'Amico et al. 2006). However, for solid fruits and vegetables microbial reductions are not so significant. Alegria et al. (2009) reported 1.7 and $1.2 \log$ reduction for total aerobic plate counts and yeasts and moulds, respectively, when studying the impact of thermosonication $\left(45 \mathrm{kHz}\right.$ and $\left.50{ }^{\circ} \mathrm{C}\right)$ on carrots. Cao et al. (2010) applied ultrasounds $(25 \mathrm{kHz})$ to strawberries and observed 0.88 and $1.1 \mathrm{log}$ reductions for aerobic microorganisms and moulds and yeast, respectively.

In terms of food quality characteristics, ultrasounds may have positive or negative impacts. It has been found for watercress that thermosonication (using temperatures above $85{ }^{\circ} \mathrm{C}$ ) is more efficient on peroxidase inactivation than conventional heat blanching (Cruz et al. 2006, 2007). However, Gabaldón-Leyva et al. (2007) observed a harmful effect of ultrasounds on firmness and water losses in brine bell peppers.

UV radiation is another non-thermal technology that has been used to control post-harvest contamination and to extend shelf-life of fruits and vegetables. UV-C (200$280 \mathrm{~nm}$ ) has a germicidal effect, inactivating bacteria, viruses, protozoa, yeasts, molds and algae (Anonymous 2000; Zenoff et al. 2006; Keyser et al. 2008; Caminiti et al. 2010). Allende et al. (2006) investigated UV-C resistance of 20 bacterial strains from different genera often associated with fresh produce. The radiation has been proven to be effective on reducing psychrotrophic bacteria, coliforms and yeast loads in lettuce (Allende and Artés 2003a, b). This treatment also reduced mesophilic, psycrophilic and enterobacteria populations in watermelons stored under refrigerated conditions (Hernández et al. 2010), and retarded fungal growth in strawberries (Pan et al. 2004; Marquenie et al. 2002) and in zucchini squash fruit (Erkan et al. 2001). Yaun et al. (2004) applied UV-C radiation to red delicious apples, leaf lettuce and tomatoes, obtaining 3.3 and $2.79 \log$ reduction of Escherichia coli on apples and green leaf lettuce, respectively; on tomatoes and green leaf lettuce, log reductions of Salmonella spp. were 2.19 and 2.65, respectively. Even so, controversial results about the efficiency of UV-C radiation on contaminated fruits and vegetables are frequently reported (López-Rubira et al. 2005; Fonseca and Rushing 2006).

In terms of quality, UV-C treatments are often referred to be effective in delaying senescence and deterioration of the products (Allende et al. 2006; Allende and Artés 2003a, b; Pan et al. 2004). In most cases, the impact of such treatments on important quality parameters is not relevant (Vicente et al. 2005; Allende et al. 2007).
The main objective of the present work was to assess the impact of UV-C radiation and thermosonication (using conventional blanching for comparative purposes) on the following microbial loads: Listeria innocua inoculated (in red bell peppers), and endogenous total mesophiles (in strawberries) and total coliforms (in watercress). These combinations were used as case studies. Quality characteristics changes, such as colour and textural were studied for all products, since these are easily perceived by the consumer and more sensitive to processes. Anthocyanins content was studied for strawberries since this is an index of health benefit (antioxidant activity) of berries.

\section{Materials and Methods}

Fruits and Vegetables

Red bell peppers (Capsicum annuum L.), watercress (Nasturtium officinale R.Br.) and strawberries (Fragaria ananassa D.) were purchased in a local market.

Microbial Analysis

\section{Innocua Culture}

L. innocua NCTC 10528 was acquired from Leatherhead Food Research Association (Leatherhead, UK). The first subculture was made in tryptic soy broth (TSB; Lab M, Lancashire, UK), containing $0.6 \%$ yeast extract (TSBYE; Lab M) and was incubated at $30{ }^{\circ} \mathrm{C}$ for $24 \mathrm{~h}$. The cultures were maintained at $7{ }^{\circ} \mathrm{C}$ on tryptic soy agar (TSA; Lab M), supplemented with $0.6 \%$ of yeast extract (TSAYE). The second subculture of L. innocua was incubated at $30{ }^{\circ} \mathrm{C}$ for $\pm 24 \mathrm{~h}$ to yield stationary phase cultures. This cell growth phase was chosen, because the stress resistance of $L$. innocua cells is higher in that phase, in comparison with the lag or exponential phases (Miller et al. 2009).

\section{Microorganism/Food}

Three different combinations of microorganism/food were considered: L. innocua/red bell peppers, total mesophiles/ strawberries and total coliforms/watercress.

Red bell peppers were washed for a few seconds in deionised water and dried with absorbent paper. Peduncles and seeds were removed. The product was cut in portions (samples) of approximately $20 \mathrm{~g}$, which were artificially inoculated at the internal surface with $250 \mu \mathrm{l}$ (five drops of $50 \mu \mathrm{l}$ each) of the second $L$. innocua subculture. The contact time was about 15 min (till surface drying).

Strawberries and watercress were not washed, since endogenous total mesophiles and total coliforms, respectively, were enumerated. 


\section{Enumeration}

Samples were aseptically cut in small portions that were homogenised in a stomacher with $80 \mathrm{ml}$ of Buffered Peptone Water (BPW; Lab M) for 5 min.

Palcam agar containing selective supplement (Merck, Darmstadt, Germany), Plate Count Agar (PCA; Lab M) and Violet Red Bile Agar (VRBA; Lab M) were used, respectively, for $L$. innocua, total mesophiles and total coliforms enumerations (in duplicate). Samples were incubated at $30{ }^{\circ} \mathrm{C}$ for posterior counts. At least four replicates were performed.

\section{Quality Measurements}

Colour and texture were measured for all products. For strawberries, the anthocyanins content was also analysed.

\section{Colour}

Colour was measured with a handheld tristimulus colorimeter (Chroma Meter CR-400; Konica Minolta Sensing, Inc., Tokyo, Japan) using the Hunter Lab scale ( $\mathrm{L}$ varies from 0 (black) to 100 (white); a positive is red and negative is green; $b$ positive is yellow and negative is blue). The total colour difference (TCD) was the parameter considered for colour changes evaluation. This parameter quantifies the overall colour difference of a given sample when compared to a reference one, and is calculated as follows (Drlange 1994):

$\mathrm{TCD}=\sqrt{\left(a-a_{0}\right)^{2}+\left(b-b_{0}\right)^{2}+\left(L-L_{0}\right)^{2}}$

where the index " 0 " indicates untreated reference samples.

The colorimeter was properly calibrated with a standard white reference tile. At least 20 replicates were carried out.

\section{Texture}

Texture was analysed with a TA-XT2 plus texture analyser (Stable Micro Systems Ltd., Godalming, UK) equipped with a $5 \mathrm{~kg}$ load cell. Compression mode tests $(30 \%$ deformation, $1 \mathrm{~mm} \mathrm{~s}^{-1}$ velocity) were performed using a $10 \mathrm{~mm}$ or a $36 \mathrm{~mm}$ diameter cylindrical probe for red bell peppers and strawberries, respectively. For watercress samples, a perforation probe of $2 \mathrm{~mm}$ diameter was used $(0.5 \mathrm{~mm}$ penetration, $1 \mathrm{~mm} \mathrm{~s}^{-1}$ velocity). Firmness was registered as the maximum force observed during compression of samples.

The texture analyser was properly calibrated and at least 30 replicates were performed.

\section{Anthocyanins}

Strawberries were cut in small pieces and homogenised in a stomacker during $5 \mathrm{~min}$. The anthocyanins samples extraction was attained by mixing $5 \mathrm{~g}$ with $15 \mathrm{ml}$ of acetone $(70 \% \mathrm{v} / \mathrm{v})$ for $5 \mathrm{~min}$. The solution was then filtrated.

The total anthocyanin concentration was determined by the pH differential method (Giusti and Wrolstad 2001; Teow et al. 2007), using two different buffers: potassium chloride $(0.025 \mathrm{M}, \mathrm{pH} 1.0)$ and sodium acetate $(0.4 \mathrm{M}, \mathrm{pH}$ 4.5). The $\mathrm{pH}$ was adjusted with concentrated hydrochloric acid. A volume of $1.8 \mathrm{ml}$ of each buffer was mixed with $200 \mu \mathrm{l}$ of the extracted solution for $15 \mathrm{~min}$. The absorbance of the solutions was read at 510 and $700 \mathrm{~nm}$ (UV-1601; Shimadzu Co., Kyoto, Japan). At least 16 replicates were performed. The total anthocyanin content was expressed as the mass $(\mathrm{mg})$ of pelargonidin 3-glycoside (predominant anthocyanin in strawberries) per $100 \mathrm{~g}$ of fresh mass (Gil et al. 1997; Cordenunsi et al. 2002).

\section{Technological Treatments}

\section{Heat Blanching}

Blanching treatments were performed in a Pyrex glass recipient containing 11 of stirred deionised water (the ratio between mass of the samples and volume of water was approximately $40 \mathrm{~g}^{-1}$ ).

For quality assessment, blanching temperatures used in all products were 50 and $65^{\circ} \mathrm{C}$.

For each combination microorganism/food, different temperatures were tested due to differences in microorganisms' thermal sensitivity. For $L$. innocua/red bell peppers, blanching temperatures were 50,60 and $65{ }^{\circ} \mathrm{C}$; for total mesophiles/strawberries, the temperatures were 50 , 55,60 and $65^{\circ} \mathrm{C}$; for total coliforms/watercress, blanching treatments were performed at 50,55 and $65{ }^{\circ} \mathrm{C}$.

The treatment times for all products were $2 \mathrm{~min}$. At least three replicates of each treatment were performed.

\section{Ultrasonication and Thermosonication}

Ultrasonication treatments were carried out in an ultrasound Sonorex Super RK 106 equipment (Bandelin Electronic, Berlin, Germany) operating at $35 \mathrm{kHz}$ and $120 \mathrm{~W}$ with 5.61 of water capacity. The ratio between mass of the samples and volume of water was approximately $40 \mathrm{~g} \mathrm{l}^{-1}$. Ultrasonication was combined with heat using the same temperatures as for blanching.

The treatment times for all products were $2 \mathrm{~min}$. At least three replicates of each treatment were performed. 


\section{UV-C Radiation}

UV-C treatments were carried out in a chamber designed by University of Algarve, Portugal. Samples were submitted to a bank of four germicidal UV lamps (TUV G30T8, 16 W; Phillips, Amsterdam, The Netherlands) with peak emission at $254 \mathrm{~nm}$ and an average intensity of $12.36 \mathrm{~W} \mathrm{~m}^{-2}$, for $2 \mathrm{~min}$. The intensity of flux of lamps and dose of exposure (time $\times$ intensity) were continuously measured using an UV digital photometer (DO 9721; Delta Ohm, Padova, Italy). The temperature was also monitored $\left(25.2 \pm 1.8^{\circ} \mathrm{C}\right)$. At least three replicates of each treatment were carried out.

\section{Control Assays}

Additional experiments were performed as described in Sections 2.4.1 and 2.4.2, but at a temperature of approximately $15{ }^{\circ} \mathrm{C}$ (control of the treatments).

\section{Data Analysis}

For microbial loads, the effects of treatments were assessed by calculating the microbial reduction expressed in terms of log-cycles (i.e., $\log \left(N_{0} / N\right)$, where $N_{0}$ is the sample initial microbial load and $N$ is the microbial load after treatment).

Quality data (texture and anthocyanins) were normalized in relation to untreated samples. This means that values were divided by those determined for fresh samples.

Temperature and treatments effect were evaluated by analysis of variance (two-way ANOVA) using SPSS ${ }^{\circledR} 16.0$ for Windows ${ }^{\circledR}$ (2006 SPSS Inc., Chicago, IL, USA). Tukey's test was performed for paired comparison of means (Walpole and Myers 1993).

\section{Results and Discussion}

Impact of Treatments on Microbial Loads

The impact of heat blanching, thermosonication and UV-C radiation treatments on L. innocua (in red bell peppers, initial loads $\sim 10^{7} \mathrm{cfu} / \mathrm{g}$ ), total mesophiles (in strawberries, initial loads $\sim 10^{7} \mathrm{cfu} / \mathrm{g}$ ) and total coliforms (in watercress, initial loads $\sim 10^{8} \mathrm{cfu} / \mathrm{g}$ ) is shown in Fig. 1. Total coliforms were selected for watercress, since these microorganisms are contaminants of this vegetable. Total mesophiles were chosen for strawberries, as a representative microorganisms mixture of a fruit. L. innocua was selected as an indicator microorganism. This bacterium is often used as a surrogate of the ubiquitous pathogenic L. monocytogenes (Margolles et al. 2000).

UV-C radiation was the least effective treatment in reducing the microbial load of the tested products. With this

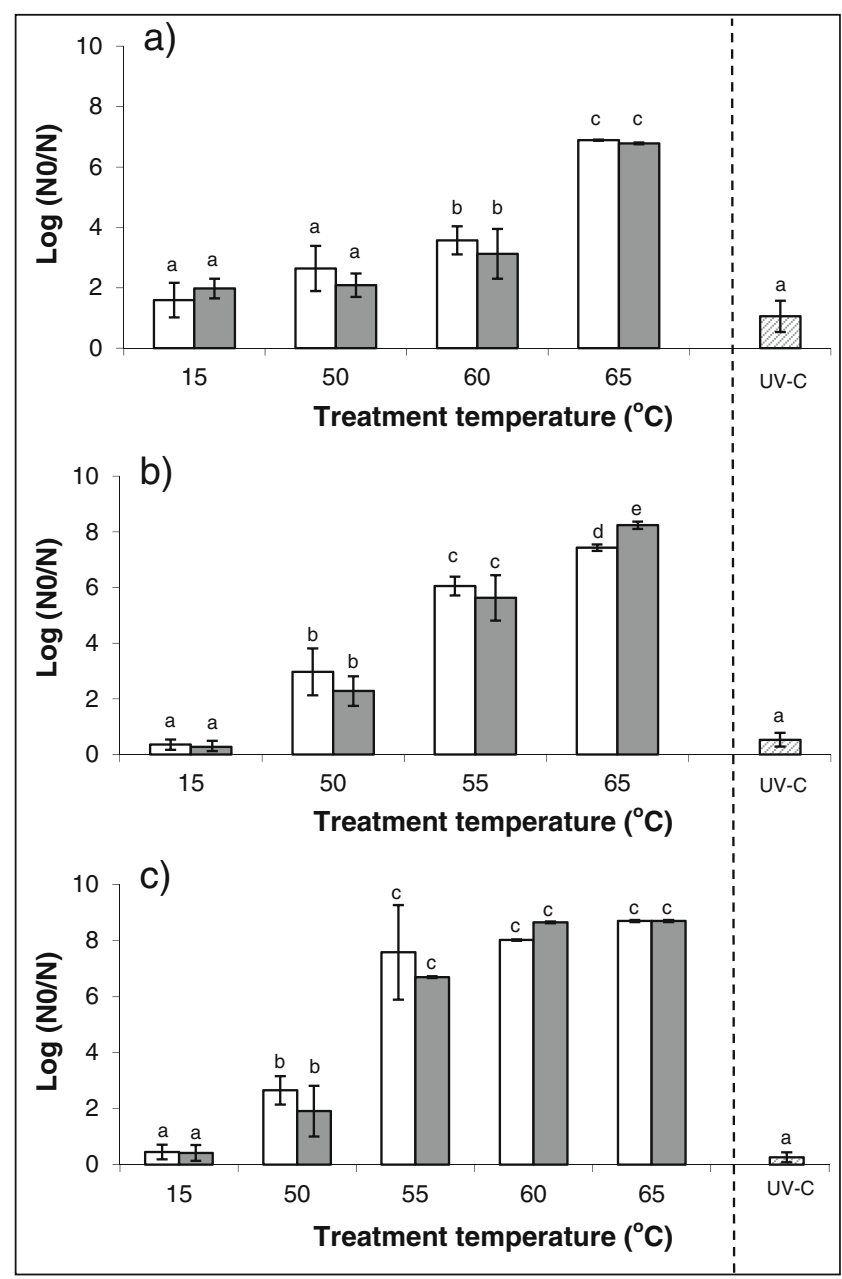

Fig. 1 Effects of water/blanching (open bars), ultrasonication/ thermosonication (closed bars) and ultraviolet radiation (hatched bars) on a Listeria innocua/red bell peppers, b total coliforms/ watercress and $\mathbf{c}$ total mesophiles/strawberries. Given are means \pm SD of at least four independent experiments. Values with different characters differ significantly $(p<0.05)$

method, log-microbial reductions were equivalent to the ones obtained with simple washings with water at $15{ }^{\circ} \mathrm{C}$ (log reductions of $1.05 \pm 0.52$ for L. innocua, $0.53 \pm 0.25$ for total coliforms and $0.26 \pm 0.18$ for total mesophiles). The germicidal effect of radiation is mainly due to the photochemical reactions that are induced inside the microorganisms. The major lesion in the microorganisms is related to DNA absorption of the UV light, taking place by cross-linking pyrimidine nucleoside bases (thymine and cytosine) in the same DNA strand. The formation of thymine dimers in DNA and RNA will compromise the cellular functions, since microorganisms are deprived to realize the normal transcription and replication of the nucleic acids and, eventually, cell death occurs (Giese and Darby 2000; Unluturk et al. 2008).

Temperature was always most effective. For all heat blanching and thermosonication treatments, reduction of 
microbial loads increased with temperature. Furthermore, $L$. innocua was most temperature resistant while total mesophiles were most temperature sensitive for both heat blanching and thermosonication.

At the same temperature, effects of thermosonication were equivalent to that of heat blanching for all microorganism/products tested, except for total coliforms/watercress at $65{ }^{\circ} \mathrm{C}$. Here, thermosonication had a significantly higher impact $(p<0.05)$ on microbial reduction. Heat blanching reduced microbial loads by $7.43 \pm 0.12$ logcycles, while loads were diminished by $8.24 \pm 0.13 \mathrm{log}$ cycles after thermosonication at the same temperature. This could be explained by a more pronounced effect of ultrasounds when higher temperatures were used. The bactericidal effect of ultrasound technology is related to intracellular pressure changes due to cavitation phenomena, which promote the disruption of cellular structures and functional components and cause cellular lysis (Anonymous 2000; Ross et al. 2003).

The reduction of total mesophiles on strawberries obtained in this study are of the same magnitude as those reported by Alegria et al. (2009) on the effect of ultrasonication $(1 \mathrm{~min} / 45 \mathrm{kHz})$ and thermosonication $(1 \mathrm{~min} /$ $50{ }^{\circ} \mathrm{C}$ ) on total aerobic plate counts and yeasts and moulds in carrots. These authors reported 0.5 log-cycles reduction for both type of microorganisms in ultrasonicated samples, and 1.7 and $1.2 \log$ reduction for total aerobic plate counts and yeasts and moulds, respectively, in thermosonicated samples. Cao et al. (2010) tested several ultrasonic frequencies on strawberries and observed 0.88 and $1.1 \mathrm{log}$ reductions for aerobic microorganisms and moulds and yeasts, respectively ( $25 \mathrm{kHz}$ for $10 \mathrm{~min}$ of treatment). These results are slightly higher than the ones obtained in the present work (but the treatment time was five times higher). Noci et al. (2009) used thermosonication $\left(24 \mathrm{kHz}\right.$ and $55^{\circ}$ C) to inactivate $L$. innocua in milk samples. A treatment time of $2.7 \mathrm{~min}$ allowed approximately 1 log-cycle reduction.

Energy requirements for each process and combination of microorganism/food were calculated. Results were expressed in terms of log-cycles reduction per unit energy consumed (Table 1). This allows quantification and comparison of the processes effectiveness in terms of impact at microbiological level and operation cost. For all combinations of microorganism/food, blanching and thermosonication at the highest temperatures were the most efficient processes it terms of energy consumption and impact in microbial load reduction, since they allowed higher log-cycles reduction per unit of energy. For $L$. innocua/red bell peppers, UV-C treatment is the second in
Table 1 Log cycles reduction per unity energy consumption for each process and each combination of microorganism/ food (results are sorted from the highest to smallest value)

\begin{tabular}{|c|c|c|}
\hline Microorganism/food & Treatment (3 min) & $\begin{array}{l}\text { Log-cycles reduction/ } \\
\text { energy } \times 10^{4}((\log \mathrm{g}) / \mathrm{J})\end{array}$ \\
\hline \multirow[t]{7}{*}{ Listeria innocua/red bell pepper } & Blanching $65^{\circ} \mathrm{C}$ & 5.1 \\
\hline & UV-C & 5.0 \\
\hline & Thermosonication $65^{\circ} \mathrm{C}$ & 4.8 \\
\hline & Blanching $60{ }^{\circ} \mathrm{C}$ & 3.2 \\
\hline & Blanching $50{ }^{\circ} \mathrm{C}$ & 2.7 \\
\hline & Thermosonication $60{ }^{\circ} \mathrm{C}$ & 2.6 \\
\hline & Thermosonication $50{ }^{\circ} \mathrm{C}$ & 2.0 \\
\hline \multirow[t]{7}{*}{ Total coliforms/watercress } & Thermosonication $65^{\circ} \mathrm{C}$ & 5.9 \\
\hline & Blanching $65^{\circ} \mathrm{C}$ & 5.5 \\
\hline & Blanching $55^{\circ} \mathrm{C}$ & 5.4 \\
\hline & Thermosonication $55^{\circ} \mathrm{C}$ & 4.8 \\
\hline & Blanching $50{ }^{\circ} \mathrm{C}$ & 3.0 \\
\hline & UV-C & 2.5 \\
\hline & Thermosonication $50{ }^{\circ} \mathrm{C}$ & 2.2 \\
\hline \multirow[t]{9}{*}{ Total mesophiles/strawberry } & Thermosonication $60{ }^{\circ} \mathrm{C}$ & 6.8 \\
\hline & Blanching $55^{\circ} \mathrm{C}$ & 6.7 \\
\hline & Blanching $60{ }^{\circ} \mathrm{C}$ & 6.6 \\
\hline & Blanching $65^{\circ} \mathrm{C}$ & 6.4 \\
\hline & Thermosonication $65^{\circ} \mathrm{C}$ & 6.2 \\
\hline & Thermosonication $55^{\circ} \mathrm{C}$ & 5.7 \\
\hline & Blanching $50{ }^{\circ} \mathrm{C}$ & 2.7 \\
\hline & Thermosonication $50{ }^{\circ} \mathrm{C}$ & 1.8 \\
\hline & UV-C & 1.3 \\
\hline
\end{tabular}


the rank. However, one should bear in mind that this treatment, in terms of microbial load reduction, is merely equivalent to a simple water washing.

\section{Impact of Treatments on Quality Factors}

Results of quality parameters (colour, texture and anthocyanins) of red bell peppers, watercress and strawberries are shown in Figs. 2, 3 and 4.

UV-C irradiation had the lowest impact on product colour (Fig. 2). TCD of UV-C-treated red bell pepper and watercress samples were $1.30 \pm 0.66$ and $1.58 \pm 0.77$, respectively (Fig. 2a, b). These values were significantly lower than those observed for samples that were simply washed with water at $15{ }^{\circ} \mathrm{C}$. According to Drlange (1994), these colour differences are classified as small. TCD of water-

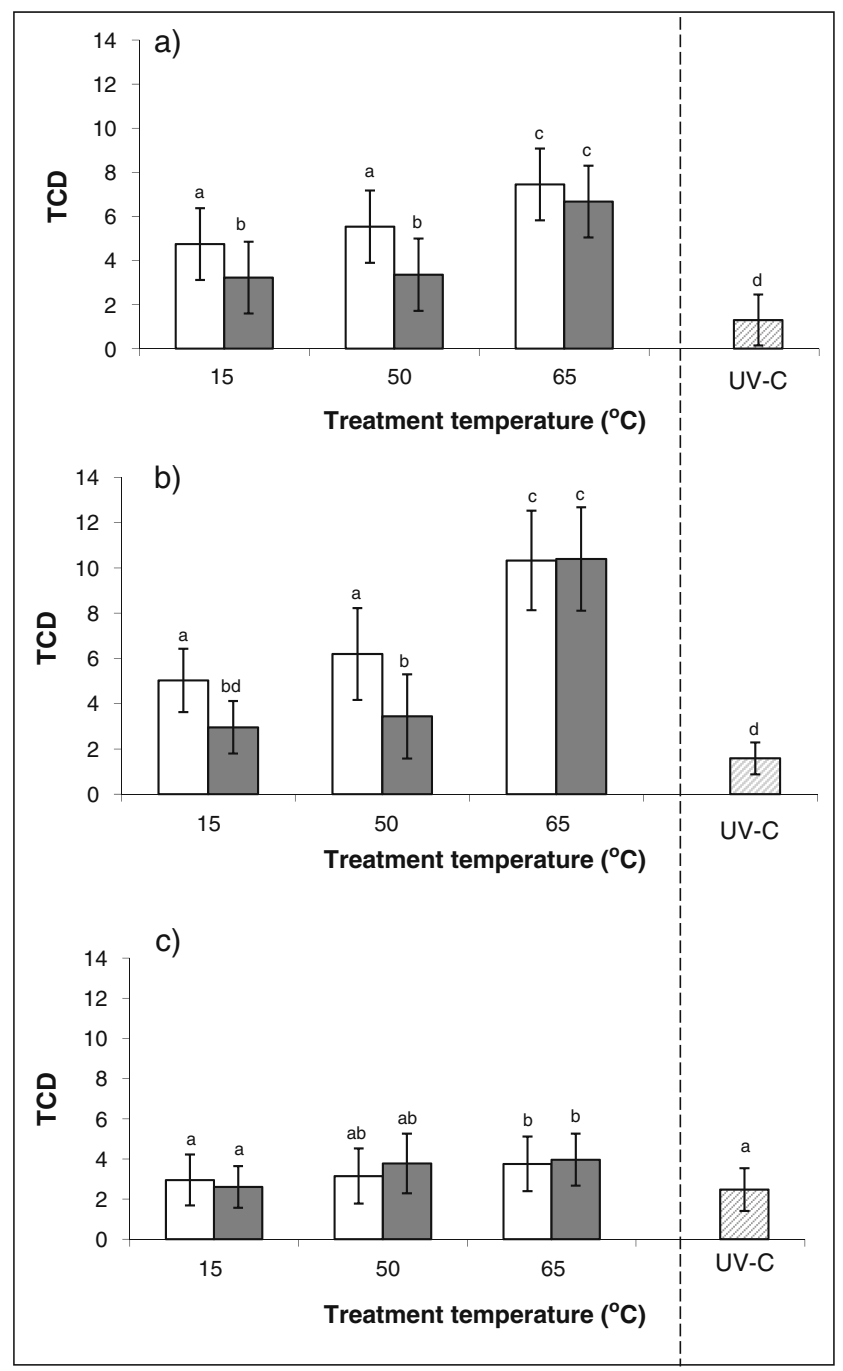

Fig. 2 Effect of water/blanching (open bars), ultrasonication/thermosonication (closed bars) and ultraviolet radiation (hatched bars) on total colour difference (TCD) of a red bell pepper, b watercress and c strawberry samples. Given are means \pm SD of at least 20 independent experiments. Values with different characters differ significantly $(p<0.05)$

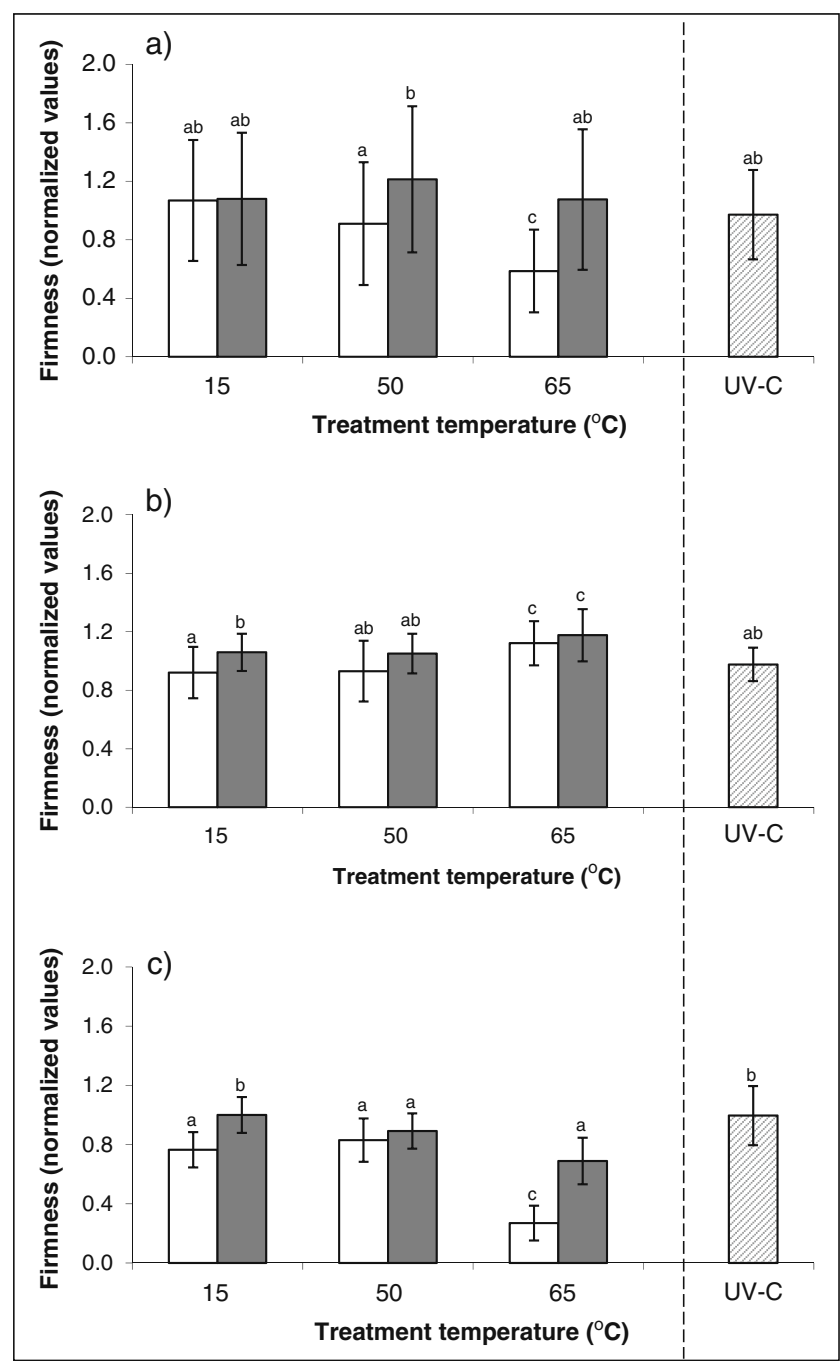

Fig. 3 Effect of water/blanching (open bars), ultrasonication/thermosonication (closed bars) and ultraviolet radiation (hatched bars) on firmness, normalized in terms of untreated samples, of a red bell pepper, b watercress and c strawberry samples. Given are means \pm SD of at least 30 independent experiments. Values with different characters differ significantly $(p<0.05)$

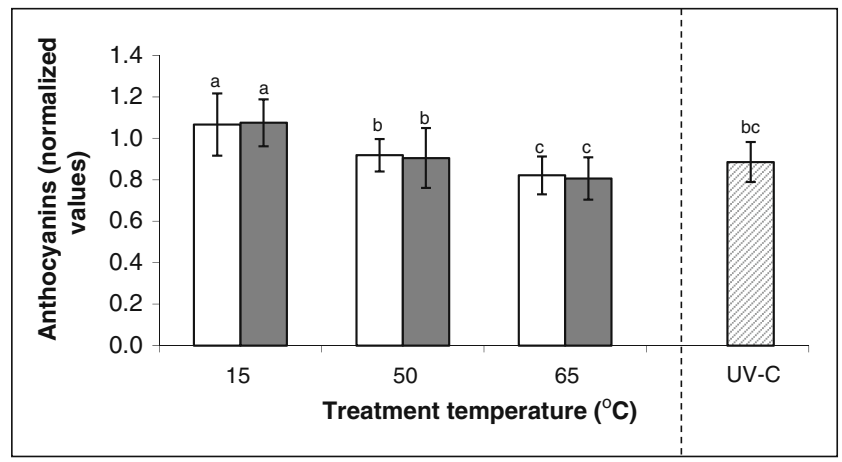

Fig. 4 Effect of water/blanching (open bars), ultrasonication/thermosonication (closed bars) and ultraviolet radiation (hatched bars) on total anthocyanins of strawberries, normalized in terms of untreated samples. Given are means \pm SD of at least 16 independent experiments. Values with different characters differ significantly $(p<0.05)$ 
washed strawberries (Fig. 2c) were equivalent to the values observed for samples that were treated with UV-C (2.47士 1.08), generally rated as distinct differences (Drlange 1994).

For 15 and $50{ }^{\circ} \mathrm{C}$, the differences in colour of red bell pepper and watercress treated with ultrasounds were significantly lower $(p<0.05)$ than those observed for water washing and heat blanching at the same temperatures. This means that thermosonication retained sample colour better than the other treatments. For strawberries, the differences between the heat blanched and thermosonicated samples were not significant at all temperatures. For watercress and red bell peppers, the differences were not evident only at $65{ }^{\circ} \mathrm{C}$. At this temperature, colour changes were pronounced for watercress but only small for strawberries.

Firmness of thermosonicated samples was equal or better retained than firmness of heat blanched samples, at the same temperatures. This is particularly evident for peppers at 50 and $65{ }^{\circ} \mathrm{C}$, and for strawberries at $65^{\circ} \mathrm{C}$ (Fig. 3).

Compared to untreated samples, firmness of UV-C irradiated samples was maintained better. For peppers and watercress, the effects of UV-C radiation were equivalent to water washings.

The impact of the treatments on anthocyanins content of strawberries is shown in Fig. 4. As temperature increases, a slight decrease in anthocyanins was observed. No significant differences between heat blanched and thermosonicated samples were detected. Sonicated samples at $15{ }^{\circ} \mathrm{C}$ retained totally the anthocyanins content. However, Tiwari et al. (2009) reported a decrease of $5 \%$ in anthocyanins content when sonication $(20 \mathrm{kHz})$ was applied to blackberry juice.

UV-C radiation treatment allowed retention of $89 \pm 10 \%$ of antocyanins content, which was equivalent to heat blanching and thermosonication at $50{ }^{\circ} \mathrm{C}$.

\section{Conclusions}

In terms of microbial reduction, UV-C radiation was the least effective treatment being equivalent to a simple water washing (at $15^{\circ} \mathrm{C}$ ). Thermosonication and heat blanching at 50,55 and $60^{\circ} \mathrm{C}$ allowed similar reductions in microbial loads for all the products studied. For the case of total coliforms/watercress at $65{ }^{\circ} \mathrm{C}$, thermosonication had a higher impact on coliforms reduction.

UV-C irradiation showed the lowest impact on the quality parameters analysed. Compared to traditional heat blanching, thermosonication always retained quality better at the same temperature.

The effects of thermosonication on microbial loads were significant and adverse impacts of this treatment on studied food quality attributes were equivalent or lower than the ones observed with heat blanching. Hence, it can be concluded that thermosonication is a potential alternative to conventional thermal treatments, with energy requirements equivalent of the ones of blanching.

Acknowledgements The authors acknowledge the financial support through Programa Operacional Agricultura e Desenvolvimento RuralProjecto AGRO no. 822 (Novas Tecnologias de Processamento de Hortofrutículas Congelados-EMERCON). The authors Alexandre E. M.C., Santos Pedro, D.M.J. and Brandão T.R.S. would like to thank Fundação para a Ciência e a Tecnologia (grants SFRH/BD/16042/2004, SFRH/BPD/9174/2002 and SFRH/BPD/11580/2002, respectively).

\section{References}

Ahvenainen, R. (1996). New approaches in improving the shelf life of minimally processed fruit and vegetables. Trends in Food Science \& Technology, 7(6), 179-187.

Alegria, C., Pinheiro, J., Gonçalves, E. M., Fernandes, I., Moldão, M., \& Abreu, M. (2009). Quality attributes of shredded carrot (Daucus carota L. cv. Nantes) as affected by alternative decontamination processes to chlorine. Innovative Food Science \& Emerging Technologies, 10(1), 61-69.

Allende, A., \& Artés, F. (2003a). UV-C radiation as a novel technique for keeping quality of fresh processed 'Lollo Rosso' lettuce. Food Research International, 36(7), 739-746.

Allende, A., \& Artés, F. (2003b). Combined ultraviolet-C and modified atmosphere packaging treatments for reducing microbial growth of fresh processed lettuce. Lebensmittel-Wissenschaft und-Technologie, 36(8), 779-786.

Allende, A., Marín, A., Buendía, B., Tomás-Barberán, F., \& Gil, M. I. (2007). Impact of combined postharvest treatments (UV-C light, gaseous $\mathrm{O}_{3}$, superatmospheric $\mathrm{O}_{2}$ and high $\mathrm{CO}_{2}$ ) on health promoting compounds and shelf-life of strawberries. Postharvest Biology and Technology, 46(3), 201-211.

Allende, A., McEvoy, J. L., Luo, Y., Artes, F., \& Wang, C. Y. (2006). Effectiveness of two-sided UV-C treatments in inhibiting natural microflora and extending the shelf-life of minimally processed 'Red Oak Leaf' lettuce. Food Microbiology, 23(3), 241-249.

Anonymous (2000). Kinetics of microbial inactivation for alternative food processing technologies. Center for food safety and applied nutrition, U. S. Food and Drug Administration

Baumann, A. R., Martin, S. E., \& Feng, H. (2005). Power ultrasound treatment of Listeria monocytogenes in apple cider. Journal of Food Protection, 68(11), 2333-2340.

Caminiti, I. M., Palgan, I., Muñoz, A., Noci, F., Whyte, P., Morgan, D. J., Cronin, D. A., \& Lyng, J. G. (2010). The effect of ultraviolet light on microbial inactivation and quality attributes of apple juice. Food Bioprocess Technology, doi:10.1007/s11947-0100365-X, in press.

Cao, S., Hu, Z., Pang, B., Wang, H., Xie, H., \& Wu, F. (2010). Effect of ultrasound treatment on fruit decay and quality maintenance in strawberry after harvest. Food Control, 21(4), 529-532.

Char, C. D., Mitilinaki, E., Guerrero, S. N., \& Alzamora, S. M. (2010). Use of high-intensity ultrasound and UV-C light to inactivate some microorganisms in fruit juices. Food Bioprocess Technology, 3, 797-803.

Cordenunsi, B. R., Nascimento, J. R. O., Genovese, M. I., \& Lajolo, F. M. (2002). Influence of cultivar on quality parameters and chemical composition of strawberry fruits grown in Brazil. Journal of Agricultural and Food Chemistry, 50, 2581-2586. 
Cruz, R. M. S., Vieira, M. C., \& Silva, C. L. M. (2006). Effect of heat and thermosonication treatments on peroxidase inactivation kinetics in watercress (Nasturtium officinale). Journal of Food Engineering, 72(1), 8-15.

Cruz, R. M. S., Vieira, M. C., \& Silva, C. L. M. (2007). Modelling kinetics of watercress Nasturtium officinalecolour changes due to heat and thermosonication treatments. Innovative Food Science \& Emerging Technologies, 8(2), 244-252.

Cruz, R. M. S., Vieira, M. C., Fonseca, S. C., \& Silva, C. L. M. (2009). Impact of thermal blanching and thermosonication treatments on watercress (Nasturtium officinale) quality: thermosonication process optimisation and microstructure evaluation. Food Bioprocess Technology, doi:10.1007/s11947-009-0220-0, in press.

D’Amico, D. J., Silk, T. M., Wu, J. R., \& Guo, M. R. (2006). Inactivation of microorganisms in milk and apple cider treated with ultrasounds. Journal of Food Protection 69(3), 556-563.

Drlange (1994). Colour review. Drlange Application Report, No. 8. DrLange, USA.

Erkan, M., Wang, C. Y., \& Krizek, D. T. (2001). UV-C irradiation reduces microbial populations and deterioration in Cucurbita pepo fruit tissue. Environmental and Experimental Botany, 45(1), $1-9$

Fonseca, J. M., \& Rushing, J. W. (2006). Effect of ultraviolet-C light on quality and microbial population of fresh-cut watermelon. Postharvest Biology and Technology, 40(3), 256-261.

Gabaldón-Leyva, C. A., Quintero-Ramos, A., Barnard, J., BalandránQuintana, R. R., Talamás-Abbud, R., \& Jiménez-Castro, J. (2007). Effect of ultrasound on the mass transfer and physical changes in brine bell pepper at different temperatures. Journal of Food Engineering, 81(2), 374-379.

Giese, N., \& Darby, J. (2000). Sensitivity of microorganisms to different wavelengths of UV light: implications on modeling of medium pressure UV systems. Water Research, 34(16), 40074013.

Gil, M. I., Holcroft, D. M., \& Kader, A. A. (1997). Changes in strawberry anthocyanins and other polyphenols in response to carbon dioxide treatments. Journal of Agricultural and Food Chemistry, 45, 1662-1667.

Giusti, M. M., \& Wrolstad, R. E. (2001). Characterization and measurement of anthocyanins by UV-visible spectroscopy. Current protocols in food analytical chemistry, F1.2.1-F1.2.13.

Hernández, A. F., Robles, P. A., Gómez, P. A., Callejas, T. A., \& Artés, F. (2010). Low UV-C illumination for keeping overall quality of fresh-cut watermelon. Postharvest Biology and Technology, 55, 114-120.

Keyser, M., Muller, I. A., Cilliers, F. P., Nel, W., \& Gouws, P. A. (2008). Ultraviolet radiation as a non-thermal treatment for the inactivation of microorganisms in fruit juice. Innovative Food Science \& Emerging Technologies, 9(3), 348-354.

Knorr, D., Zenker, M., Heinz, V., \& Lee, D.-U. (2004). Applications and potential of ultrasonics in food processing. Trends in Food Science \& Technology, 15(5), 261-266.

López-Rubira, V., Conesa, A., Allende, A., \& Artés, F. (2005). Shelf life and overall quality of minimally processed pomegranate arils modified atmosphere packaged and treated with UV-C. Postharvest Biology and Technology, 37(2), 174-185.

Margolles, A., Mayo, B., \& Reyes-Gavilán, C. G. (2000). Phenotypic characterization of Listeria monocytogenes and Listeria innocua strains isolated from short-ripened cheeses. Food Microbiology, 17(4), 461-467.
Marquenie, D., Michiels, C. W., Geeraerd, A. H., Schenk, A., Soontjen, C., Van Impe, J. F., \& Nicoläi, B. M. (2002). Using survival analysis to investigate the effect of UVC and heat treatment on storage rot of strawberry and sweet cherry. International Journal of Food Microbiology, 73(2-3), 187-196.

Mason, T. J., Paniwnyk, L., \& Lorimer, J. P. (1996). The uses of ultrasound in food technology. Ultrasonics Sonochemistry, 3(3), S253-S260.

Miller, F. A., Gil, M. M., Brandão, T. R. S., Teixeira, P., \& Silva, C. L. M. (2009). Sigmoidal thermal inactivation kinetics of Listeria innocua in broth: Influence of strain and growth phase. Food Control, 20(12), 1151-1157.

Mukherjee, S., \& Chattopadhyay, P. K. (2007). Whirling bed blanching of potato cubes and its effects on product quality. Journal of Food Engineering, 78(1), 52-60.

Noci, F., Walkling-Ribeiro, M., Cronin, D. A., Morgan, D. J., \& Lyng, J. G. (2009). Effect of thermosonication, pulsed electric field and their combination on inactivation of Listeria innocua in milk. International Dairy Journal, 19(1), 30-35.

Pan, J., Vicente, A. R., Martínez, G. A., Chaves, A. R., \& Civello, P. M. (2004). Combined use of UV-C irradiation and heat treatment to improve postharvest life of strawberry fruit. Journal of the Science of Food and Agriculture, 84(14), 1831-1838.

Piyasena, P., Mohareb, E., \& McKellar, R. C. (2003). Inactivation of microbes using ultrasound: A review. International Journal of Food Microbiology, 87(3), 207-216.

Ross, A. I. V., Griffiths, M. W., Mittal, G. S., \& Deeth, H. C. (2003). Combining nonthermal technologies to control foodborne microorganisms. International Journal of Food Microbiology, 89(2-3), 125-138.

Sotome, I., Takenaka, M., Koseki, S., Ogasawara, Y., Nadachi, Y., Okadome, H., \& Isobe, S. (2009). Blanching of potato with superheated steam and hot water spray. LWT-Food Science and Technology, 42(6), 1035-1040

Teow, C. C., Truong, V.-D., McFeeters, R. F., Thompson, R. L., Pecota, K. V., \& Yencho, G. C. (2007). Antioxidant activities, phenolic and [beta]-carotene contents of sweet potato genotypes with varying flesh colours. Food Chemistry, 103(3), 829-838.

Tiwari, B. K., O'Donnell, C. P., \& Cullen, P. J. (2009). Effect of sonication on retention of anthocyanins in blackberry juice. Journal of Food Engineering, 93(2), 166-171.

Unluturk, S., AtIlgan, M. R., Handan Baysal, A., \& Tari, C. (2008). Use of UV-C radiation as a non-thermal process for liquid egg products (LEP). Journal of Food Engineering, 85 (4), 561-568

Vercet, A., Lopez, P., \& Burgos, J. (1997). Inactivation of heatresistant lipase and protease from Pseudomonas fluorescens by nanothermosonication. Journal of Dairy Science, 80(1), 29-36.

Vicente, A. R., Pineda, C., Lemoine, L., Civello, P. M., Martinez, G. A., \& Chaves, A. R. (2005). UV-C treatments reduce decay, retain quality and alleviate chilling injury in pepper. Postharvest Biology and Technology, 35(1), 69-78.

Walpole, R. E., \& Myers, R. H. (1993). Probability and statistics for engineers and scientists. New York, NY: Macmillan.

Yaun, B. R., Sumner, S. S., Eifert, J. D., \& Marcy, J. E. (2004). Inhibition of pathogens on fresh produce by ultraviolet energy. International Journal of Food Microbiology, 90(1), 1-8.

Zenoff, V. F., Sineriz, F., \& Farías, M. E. (2006). Diverse responses to UV-B radiation and repair mechanisms of bacteria isolated from high-altitude aquatic environments. Applied and Environmental Microbiology, 72(12), 7857-7863. 